Strategic Financial Innovation in

Segmented Markets

By

Rohit Rahi

Jean-Pierre Zigrand

DISCUSSION PAPER NO 595

DISCUSSION PAPER SERIES

September 2007

Rohit Rahi obtained his Ph.D. in Economics from Stanford University in 1993. He is a Reader in Finance and Economics and a member of the Financial Markets Group at the London School of Economics. His research interests are in the theory of financial markets, in particular arbitrage in segmented markets, security design, and asset pricing with asymmetric information; and in general equilibrium theory with incomplete markets. He has published articles in the Review of Economic Studies, Journal of Economic Theory, and Journal of Business. He served a nine-year term on the editorial board of the Review of Economic Studies. Jean-Pierre Zigrand is a lecturer at the London School of Economics. His research interests are Asset Pricing, Financial Intermediation Theory, and General Equilibrium Theory. Any opinions expressed here are those of the authors and not necessarily those of the FMG. The research findings reported in this paper are the result of the independent research of the authors and do not necessarily reflect the views of the LSE. 


\title{
Strategic Financial Innovation in Segmented Markets*
}

\author{
by \\ Rohit Rahi \\ Department of Finance, \\ Department of Economics, \\ and Financial Markets Group, \\ London School of Economics, \\ Houghton Street, London WC2A $2 A E$ \\ and \\ Jean-Pierre Zigrand \\ Department of Finance \\ and Financial Markets Group, \\ London School of Economics, \\ Houghton Street, London WC2A $2 A E$
}

September 25, 2007.

${ }^{*}$ This paper has benefited from comments by Antoine Faure-Grimaud, Pete Kyle, Joel Peress and especially Dimitri Vayanos. We also thank seminar participants at UC Berkeley, Cambridge, London Business School, Maastricht, Oxford, Stockholm School of Economics, the European Finance Association Meetings, and the NBER/NSF General Equilibrium conference at UC Davis. 


\begin{abstract}
We study a model with restricted investor participation in which strategic arbitrageurs reap profits by exploiting mispricings across different market segments. We endogenize the asset structure as the outcome of a security design game played by the arbitrageurs. The equilibrium asset structure depends realistically upon considerations such as depth and gains from trade. It is neither complete nor socially optimal in general; the degree of inefficiency depends upon the heterogeneity of investors.
\end{abstract}

Journal of Economic Literature classification numbers: G12, D52.

Keywords: Security design, arbitrage, intermediation, market segmentation. 


\section{Introduction}

The optimal design of traded securities has been the subject of a growing body of research. The focus in the literature has been on innovations carried out by agents who do not themselves trade the securities they design, such as options or futures exchanges, entrepreneurs who sell equity stakes in their firms, or abstract social planners. In reality, agents involved in financial innovation are often profitseeking institutions that actively make markets and trade the new securities across markets, for arbitrage or hedging purposes. A large chunk of their profits comes from proprietary trading, and not simply from transaction fees received from investors. The profits of the innovating agents arise from bid-ask spreads, as well as from price differentials across markets or investor clienteles. Moreover, financial innovators are typically not price-takers but large strategic institutions who know how their actions affect prices. In this paper we propose a model that captures these features.

As an illustration, consider the following concrete examples. Trading opportunities exist between an exchange-traded fund (ETF) and the underlying portfolio of shares (the "basket"). This arbitrage is one of the main motivations behind the creation of ETFs by their sponsors, typically large brokers or specialists. The sponsors, also known as "authorized participants," can create and redeem ETF shares by swapping the basket for an ETF share and vice versa. For example, if the ETF is trading at a discount relative to the basket, an authorized participant can deliver an ETF share and receive the basket. Other investors cannot exploit this arbitrage because they are excluded from the creation-redemption process. They must instead employ a conventional long-short strategy which relies on mean-reversion in the discount over time. Moreover, discounts (and premia) are typically within the bid-ask spread for ETF shares (Engle and Sarkar (2006)).

Similarly, profit opportunities may arise between derivatives exchanges and the underlying markets. For instance, differential marginal valuations may lead to a relative mispricing between the $\mathrm{S} \& \mathrm{P} 500$ futures traded in Chicago and the basket of underlying stocks traded in New York. By introducing exchange-traded derivatives, exchanges open up such opportunities for their members. Even within an exchange, such arbitrages are possible, either across related derivatives, or simply due to bidask spreads which capture the difference between the marginal valuations of buyers and sellers. Anecdotal evidence suggests that, depending on markets and trading conditions, a fair number of trades are matched directly, exposing market makers to no risk.

Mispricings that are a source of arbitrageur profits are even more apparent in over-the-counter (OTC) markets. For instance, consider the issuer of an arbitrage collateralized debt obligation (CDO). In its cash form, the issuer purchases negotiable assets, typically high-yield bonds, which it then uses as collateral for securitization. The various tranches of the securitization are designed to suit the specific demands of different clienteles. The optimal design of the tranches ${ }^{1}$ maximizes the arbitrage

\footnotetext{
${ }^{1}$ Issuers are able to optimize the designed securities along several dimensions. A careful choice
} 
profits of the issuer, which are equal to the difference between the price received for the new securities and the price paid for the collateral. Only the issuer of the CDO can exploit this arbitrage. Issuing a CDO is difficult and costly. It requires first-class distribution capabilities, and typical upfront setup costs are in the region of $\$ 5$ million.

Or consider the new and fast-growing category of property derivatives known as property total return swaps (TRSs). The intermediaries involved in these derivatives are banks, specialized interdealer brokers and spread betting companies, often in collaboration with real estate brokers for their local knowledge. Typically, one party to the swap, called the the total return payer, is endowed with an amount of physical property (e.g. developers, shopping mall owners) and wishes to hedge against movements in the property market, while the other party, the total return receiver, wishes to invest in the property market in order to diversify. The total return payer pays the receiver the rate of return on a property index in exchange for a fixed or floating interest rate on the notional amount of the swap. Thus the total return payer makes a synthetic sale of property and the total return receiver makes a synthetic purchase by paying interest. Direct investment in property, on the other hand, is difficult and costly, with nonnegligible barriers to entry. ${ }^{2}$

One common thread underlying these examples is that securities are designed by innovators who extract profits by exploiting differences in marginal investor valuations. The innovators desire as little downside risk as possible. In practice this leads to financial innovations that are redundant to a certain extent, in the sense that they can be satisfactorily replicated (or superreplicated) via a portfolio of the existing assets, at least by the most sophisticated and low-cost institutions. This raises the question why investors who buy such an innovation, say a structured product sold at a markup by an investment bank, do not replicate it themselves instead, and thereby pocket the price differential. There are many reasons that come to mind-limited knowledge regarding the right hedging strategy, high transaction costs, high setup costs involved in buying a seat on an exchange or obtaining access to real-time data and trading as required by delta-hedging, etc. In the case of ETFs and arbitrage CDOs, for example, the arbitrage trade is effectively open only to the authorized participants and the issuers, respectively. In the TRS example, trading in the underlying is costly or restricted, and price discovery is difficult.

In this paper, such impediments to perfect and costless replication are captured in the assumption that various investor groups have restricted access to capital markets. Their marginal valuations are therefore typically not equalized. The question we would like to address then is the following: given markets with differential marginal valuations, which securities are introduced by profit-maximizing innovators? And

of the attachment points of subordination, which defines the tranches, allows them to exploit the analysis methods of the rating agencies, and thereby indirectly to select the clienteles to which the tranches can be marketed. Issuers can also choose the collateral strategically; for instance a higher degree of illiquidity would procure higher yields.

${ }^{2}$ For instance, acquisition costs of property in the UK are around $8 \%$, and in many countries the costs are higher still. Some jurisdictions outright disallow foreigners from purchasing property. 
what are the welfare properties of these innovations?

That trading occurs locally and might translate into exploitable arbitrage opportunities globally has been known for many centuries of course. Postlethwayt (1757) provides a fascinating account of the opportunities for arbitrage profits in the exchange network of Europe connecting London, Amsterdam, Paris and a dozen other cities in the 17th and 18th centuries. In present-day markets, the importance of financial innovation originating with intermediaries that facilitate risk-sharing for agents who find it costly to trade directly with each other has been documented by Allen and Santomero (1997). They also point to the absence of a theoretical framework to address this feature of financial markets. The present paper takes a first step in filling this gap.

We study a two-period model with asset trading at date zero and uncertainty resolved at date one. There are several market segments or "exchanges." With each exchange is associated a group of competitive investors, who for simplicity conform to a version of the CAPM. Investors may only trade the assets available on their "local" exchange. As a special case they may constitute a homogeneous clientele that does not trade within itself. In addition, there are agents who are "global" players - they are able to trade on all exchanges simultaneously. These agents profit by arbitraging away price differentials across exchanges. We refer to them as "arbitrageurs." They have zero initial wealth, so they can be interpreted as pure intermediaries. Any transfer of resources across exchanges is intermediated by the arbitrageurs.

We first solve for equilibrium for a given asset structure. This asset structure may be completely arbitrary, with the assets trading on one exchange bearing no specific relationship to those trading on another. To any amount of asset supplies by arbitrageurs to the exchanges, there corresponds a Walrasian equilibrium on each exchange. Equilibrium supplies are then determined in a Cournot game played by the arbitrageurs. The result is a unique Cournot-Walras equilibrium associated with each asset structure.

We then endogenize the asset structure as the outcome of a security design game among the arbitrageurs before any trade takes place. Arbitrageurs determine the asset structure on any given exchange by adding assets available for trade (not necessarily the same set across exchanges). In the subsequent trading game, all arbitrageurs can trade any of the securities that have been introduced, while investors can trade the securities introduced on their own exchange. An arbitrageur's payoff in the security design game is his trading profit in the ensuing Cournot-Walras equilibrium. The arbitrageurs can thus be viewed as intermediaries who can target their clients according to their needs and supply them with securities that were hitherto unavailable to them but may be globally redundant. The financial innovations together with the inter-market trades can be viewed as a means of integrating the various markets.

We show that there is a unique equilibrium of the security design game in which there is a single asset on each exchange. In the case in which there are only two exchanges, this asset is the difference between the autarky (absent arbitrageur activ- 
ity) state-price deflators of these exchanges. In the case of multiple exchanges, the equilibrium asset on an exchange is the difference between its autarky state-price deflator and a weighted sum of the autarky state-price deflators of all exchanges. This weighted sum is in fact the complete-markets Walrasian state-price deflator of the entire integrated economy. The intuition for this result is that by buying their own state-price deflator, investors on a given exchange effectively sell their exchange-specific idiosyncratic aggregate endowment, and by simultaneously selling the Walrasian state-price deflator they buy a fraction of the overall aggregate endowment, thereby diversifying their risk. Since diversification is optimal for investors, arbitrageurs extract the maximal amount of profits by offering this economical and desired security structure. If we view the various exchanges as representing countries, we find a version of Shiller's "macro markets" (Shiller (1993)).

The equilibrium security design is optimal for arbitrageurs in the sense that no other asset structure yields higher arbitrageur profits. Furthermore, if investors on each exchange are identical, but possibly heterogeneous across exchanges, the equilibrium asset structure is actually Pareto optimal (though the equilibrium allocation is not, since arbitrageurs are imperfectly competitive). Relative to an arbitrary initial asset structure, however, equilibrium innovation by arbitrageurs may hurt some investors. We characterize who wins and who loses, and provide sufficient conditions for all investors to gain. Finally, we note that if there are heterogeneous investors within exchanges, the equilibrium security design fails to be Pareto optimal, since arbitrageurs profit only from trade between exchanges and not from trade within exchanges. They might therefore not offer the precise assets that would allow investors to exhaust gains from trade within an exchange.

One contribution of our paper is to endogenously derive an asset structure which is incomplete, without imposing a bound on the number of assets that may be introduced. Moreover, the assets that arbitrageurs innovate in our model may be redundant from the economy-wide perspective. This is an aspect of actual financial innovation that has often been remarked on in the literature, but cannot be accounted for by previous research that has focused for the most part on frictionless environments. Beyond the security design results, our model provides an explicit characterization of intermediation across segmented markets with an arbitrary asset structure. These intermediaries may be interpreted as agents traditionally thought of as arbitrageurs, such as hedge funds or proprietary trading desks of investment banks, or as market makers trading a given set of securities.

The paper is organized as follows. We introduce the framework and notation in Section 2. In Section 3 we solve for the equilibrium of the trading game for an arbitrary asset structure. Still maintaining an exogenous asset structure, we investigate the role of arbitrageurs in integrating markets in Section 4. Our security design and welfare results are in Sections 5 and 6 respectively. We relate macro markets to our setup in Section 7. In Section 8 we review the literature, in particular the theoretical research on security design and the empirical evidence on segmented markets. Section 9 concludes. Proofs of results in the main text are collected in the 
Appendix.

\section{The Setup}

We consider a two-period economy in which assets are traded at date 0 and pay off at date 1. Assets are traded in several locations or "exchanges." They are in zero net supply. We do not impose complete markets or the existence of a riskless asset.

Investor $i \in I^{k}:=\left\{1, \ldots, I^{k}\right\}$ on exchange $k \in K:=\{1, \ldots, K\}$ has endowments $\left(\omega_{0}^{k, i}, \omega^{k, i}\right)$, where $\omega_{0}^{k, i} \in \mathbb{R}$ is his endowment at date 0 , and $\omega^{k, i}$, a (real-valued) random variable, is his endowment at date 1 . His preferences are given by quasilinear quadratic expected utility

$$
U^{k, i}\left(x_{0}^{k, i}, x^{k, i}\right)=x_{0}^{k, i}+E\left[x^{k, i}-\frac{1}{2} \beta^{k, i}\left(x^{k, i}\right)^{2}\right],
$$

where $x_{0}^{k, i} \in \mathbb{R}$ is consumption at date 0 , and $x^{k, i}$ is a random variable representing consumption at date 1 . The coefficient $\beta^{k, i}$ is positive. Investors are price-taking and can trade only on their own exchange. It will be useful later to characterize exchange $k$ in terms of its aggregate preference parameter $\beta^{k}:=\left[\sum_{i}\left(\beta^{k, i}\right)^{-1}\right]^{-1}$, and its aggregate date 1 endowment $\omega^{k}:=\sum_{i} \omega^{k, i}$. Similarly we define the corresponding parameters for the entire economy: $\beta:=\left[\sum_{k}\left(\beta^{k}\right)^{-1}\right]^{-1}$ and $\omega:=\sum_{k} \omega^{k}$. Due to the non-monotonicity of quadratic utility, we need to assume that $1-\beta \omega \geq 0$. It says that the representative investor with aggregate preference parameter $\beta$ is weakly nonsatiated (has non-negative marginal utility) at the aggregate endowment $\omega$.

In addition to investors there are $N$ arbitrageurs, with typical arbitrageur $n \in$ $N:=\{1, \ldots, N\}$, who possess the technology to trade both within and across exchanges. Arbitrageurs are imperfectly competitive. They have no endowments. For simplicity, we assume that they only care about date 0 consumption.

There are $J^{k}$ assets on exchange $k$, with typical asset $j$ paying off a random quantity $d_{j}^{k}$ at date 1 . Assets on exchange $k$ can then be represented by the random payoff vector $d^{k}:=\left(d_{1}^{k}, \ldots, d_{J^{k}}^{k}\right)$. We assume that there are no redundant assets on exchange $k$. We also assume that all assets are arbitraged, i.e. traded by both the local investors and the arbitrageurs. ${ }^{3}$ The economy-wide asset structure $\left\{d^{k}\right\}_{k \in K}$ is endogenously determined as described below.

We assume that all random variables have finite support. Then we can describe the uncertainty by finitely many states of the world $s \in S:=\{1, \ldots, S\}$.

While the law of one price may not hold across exchanges, in equilibrium it must hold within any exchange. This is equivalent to the existence of a state-price deflator, one for each exchange. Given an asset price vector $q$ and asset payoff vector

\footnotetext{
${ }^{3}$ This is an innocuous assumption. It is straightforward to extend our analysis to the case where, on a given exchange, some assets are not arbitraged, i.e. traded only by investors on the exchange, while other assets are arbitraged. It turns out, however, that equilibrium prices of arbitraged assets are not affected by the payoffs of non-arbitraged assets. Thus the characteristics of non-arbitraged assets have no bearing on arbitrage trades or on security design by arbitrageurs.
} 
$d$, a random variable $p$ is called a state-price deflator if $q_{j}=E\left[d_{j} p\right]$ for every asset $j$, or more compactly, $q=E[d p]$. In the literature, the term "state-price deflator" is often used interchangeably with the terms "state-price density," "stochastic discount factor," or "pricing kernel." Much of the intuition of the present paper can be gathered from comparing state-price deflators. Since arbitrageurs are strategic, they know that their choice of asset payoffs and asset supplies affects equilibrium state-price deflators.

We model the activities of arbitrageurs as a subgame-perfect Nash equilibrium of a two-stage game. In the first stage arbitrageurs design securities, resulting in some asset structure $\left\{d^{k}\right\}_{k \in K}$. In the second stage they trade these securities. We solve the game backwards, starting with the second stage. We specify the details of the game in each stage when we come to it.

\section{Cournot-Walras Equilibrium}

In this section we analyze the trading game for exogenously given asset payoffs. Let $y^{k, n}$ be the supply of assets on exchange $k$ by arbitrageur $n$, and $y^{k}:=\sum_{n \in N} y^{k, n}$ the aggregate arbitrageur supply on exchange $k$. For given $y^{k}, q^{k}\left(y^{k}\right)$ is the marketclearing asset price vector on exchange $k$, with the asset demand of investor $i$ on exchange $k$ denoted by $\theta^{k, i}\left(q^{k}\right)$. For vectors $v, w \in \mathbb{R}^{n}, v \cdot w:=\sum_{i=1}^{n} v_{i} w_{i}$.

Definition 1 Given an asset structure $\left\{d^{k}\right\}_{k \in K}$, a Cournot-Walras equilibrium (CWE) of the economy is an array of asset price functions, asset demand functions, and arbitrageur supplies, $\left\{q^{k}: \mathbb{R}^{J^{k}} \rightarrow \mathbb{R}^{J^{k}}, \theta^{k, i}: \mathbb{R}^{J^{k}} \rightarrow \mathbb{R}^{J^{k}}, y^{k, n} \in \mathbb{R}^{J^{k}}\right\}_{k \in K, i \in I^{k}, n \in N}$, such that

1. Investor optimization: For given $q^{k}, \theta^{k, i}\left(q^{k}\right)$ solves

$$
\max _{\theta^{k, i} \in \mathbb{R}^{J^{k}}} x_{0}^{k, i}+E\left[x^{k, i}-\frac{\beta^{k, i}}{2}\left(x^{k, i}\right)^{2}\right]
$$

subject to the budget constraints:

$$
\begin{aligned}
& x_{0}^{k, i}=\omega_{0}^{k, i}-q^{k} \cdot \theta^{k, i} \\
& x^{k, i}=\omega^{k, i}+d^{k} \cdot \theta^{k, i} .
\end{aligned}
$$

2. Arbitrageur optimization: For given $\left\{q^{k}\left(y^{k}\right),\left\{y^{k, n^{\prime}}\right\}_{n^{\prime} \neq n}\right\}_{k \in K}, y^{k, n}$ solves

$$
\begin{gathered}
\max _{y^{k, n} \in \mathbb{R}^{J}} \sum_{k \in K} y^{k, n} \cdot q^{k}\left(y^{k, n}+\sum_{n^{\prime} \neq n} y^{k, n^{\prime}}\right) \\
\text { s.t. } \quad \sum_{k \in K} d^{k} \cdot y^{k, n} \leq 0 .
\end{gathered}
$$


3. Market clearing: $\left\{q^{k}\left(y^{k}\right)\right\}_{k \in K}$ solves

$$
\sum_{i \in I^{k}} \theta^{k, i}\left(q^{k}\left(y^{k}\right)\right)=y^{k}, \quad \forall k \in K
$$

Note that investors take asset prices as given, while arbitrageurs compete Cournotstyle. This equilibrium concept is due to Gabszewicz and Vial (1972), and a review can be found in Mas-Colell (1982). Arbitrageurs maximize time 0 consumption, i.e. profits from their arbitrage trades, but subject to the restriction that they are not allowed to default in any state at date 1. Equivalently, arbitrageurs need to be completely collateralized.

We first solve for Walrasian equilibrium on exchange $k$ for a given vector of asset supplies $y^{k}$. It is convenient to think of valuation in terms of state-price deflators: ${ }^{4}$

Lemma 3.1 (Market-clearing prices for given arbitrageur supplies) For given arbitrageur supply $y^{k}$, the following is a state-price deflator for exchange $k$ :

$$
\hat{p}^{k}\left(y^{k}\right):=p^{k}-\beta^{k}\left(d^{k} \cdot y^{k}\right),
$$

where $p^{k}:=1-\beta^{k} \omega^{k}$.

The function $\hat{p}^{k}\left(y^{k}\right)$ is the inverse demand function that arbitrageurs face when supplying state-contingent consumption $d^{k} \cdot y^{k}$ to exchange $k .^{5}$ The parameter $\beta^{k}$ measures the "depth" of exchange $k$ : it is the price impact of a unit of arbitrageur trading. ${ }^{6}$ For instance, ceteris paribus, the market impact of a trade is smaller on exchanges with a larger population; it can be absorbed by more investors.

Using (1), and denoting by $x^{k}:=\omega^{k}+d^{k} \cdot y^{k}$ the aggregate date 1 consumption on exchange $k$, asset prices are given by

$$
q_{j}^{k}\left(y^{k}\right)=E\left[d_{j}^{k} \hat{p}^{k}\left(y^{k}\right)\right]=E\left[d_{j}^{k}\left(1-\beta^{k} x^{k}\right)\right]=\underbrace{E\left[d_{j}^{k}\right]}_{\text {risk neutral price }}-\underbrace{\beta^{k} E\left[d_{j}^{k} x^{k}\right]}_{\text {risk aversion discount }}
$$

Thus we can interpret the price of asset $j$ on exchange $k$ as the risk neutral price from which a risk aversion discount is subtracted. The discount depends on the risk aversion parameter $\beta^{k}$ as well as on the diversification benefits of asset $j$, as measured by $E\left[d_{j}^{k} x^{k}\right]=\operatorname{cov}\left[d_{j}^{k}, x^{k}\right]+E\left[d_{j}^{k}\right] E\left[x^{k}\right]$. Ceteris paribus, the more an asset covaries with aggregate consumption, the lower its price must be in equilibrium.

\footnotetext{
${ }^{4}$ If markets are incomplete on exchange $k$, there is a multiplicity of state-price deflators $p$ for given $\left(q^{k}, d^{k}\right)$, all of which satisfy $q^{k}=E\left[d^{k} p\right]$. We will often find it convenient to choose a particular state-price deflator - it should be kept in mind that this imposes no restriction as far as asset prices are concerned.

${ }^{5}$ That $\hat{p}^{k}$ is affine in $y^{k}$ is a direct consequence of our assumption of quasilinear quadratic preferences. As is well known in Cournot theory, Cournot equilibria can only be guaranteed if inverse demand functions are affine in supplies.

${ }^{6}$ More precisely, the state $s$ value of the state-price deflator falls by $\beta^{k}$ for a unit increase in arbitrageur supply of $s$-contingent consumption.
} 
We say that exchange $k$ is in autarky if $y^{k}=0$. It is clear from (1) that $p^{k}$ is exchange $k$ 's autarky state-price deflator. The deflators $\left\{p^{k}\right\}_{k \in K}$ will play a key role in this paper. Analogous to $p^{k}, p^{k, i}:=1-\beta^{k, i} \omega^{k, i}$ is the no-trade state-price deflator of investor $(k, i)$, meaning that the investor chooses $\theta^{k, i}=0$ when faced with the deflator $p^{k, i}$.

Our assumptions on preferences, in conjunction with the absence of nonnegativity constraints on consumption, guarantee that the equilibrium pricing function on an exchange does not depend on the initial distribution of endowments, but merely on the aggregate endowment of the local investors. The autarky state-price deflator $p^{k}$ also does not depend on $d^{k}$, even though investors on exchange $k$ do trade these assets among themselves.

Before proceeding further we need to introduce some additional notation. In general, markets are incomplete on exchange $k$. Hence a random variable $x$ may not be marketable, meaning that no portfolio has $x$ as its payoff: there is no $\theta \in \mathbb{R}^{J^{k}}$ for which $x=d^{k} \cdot \theta$. The set of marketable payoffs $M^{k}$ is the set of all portfolio payoffs on exchange $k$; alternatively it is the span of $d^{k}$, denoted by $\left\langle d^{k}\right\rangle$. Thus $M^{k}:=\left\langle d^{k}\right\rangle:=$ $\left\{x: x=d^{k} \cdot \theta\right.$, for some portfolio $\left.\theta \in \mathbb{R}^{J^{k}}\right\}$. Given the linear space $M^{k}$, a random variable $x$ can be split into a marketable component $x_{M^{k}}$ and a non-marketable component $\epsilon$ in such a way that the mean-square distance between $x$ and $x_{M^{k}}$ is minimal. This marketable component $x_{M^{k}}$ is given by the least-squares regression of $x$ on $d^{k}$. In other words, there is a unique decomposition $x=x_{M^{k}}+\epsilon$, with $E\left[\epsilon d^{k}\right]=0$, and $x_{M^{k}}$ the payoff of a portfolio of the assets $d^{k}$, such that $E\left[\left(x_{M^{k}}-x\right)^{2}\right]$ is minimal.

We now solve the Cournot game among the arbitrageurs, given the inverse demand functions (1) for each $k \in K$. It turns out that there is a unique CWE, and that this equilibrium is symmetric, i.e. $y^{k, n}$ is the same for all $n$. It is convenient to state arbitrageur supplies in terms of the supply of state-contingent consumption:

Lemma 3.2 (Equilibrium supplies) Equilibrium arbitrageur supplies are unique and symmetric. For asset structure $\left\{d^{k}\right\}_{k \in K}$, they are given by

$$
d^{k} \cdot y^{k, n}=\frac{1}{(1+N) \beta^{k}}\left(p_{M^{k}}^{k}-p_{M^{k}}^{A}\right), \quad k \in K
$$

where $p^{A} \geq 0$ is a state-price deflator for the arbitrageurs.

The random variable $p^{A}$ is a state-price deflator for the arbitrageurs in the sense that it is a state-price deflator, i.e. $q^{k}=E\left[d^{k} p^{A}\right]$ for all $k$, and moreover $p^{A}(s)$ is the arbitrageurs' marginal shadow value of consumption in state $s$ (formally, as shown in the proof of Lemma 3.2, $p^{A}(s)$ is the Lagrange multiplier attached to the arbitrageurs' no-default constraint in state $s$ ). Assuming for the moment that $p^{k}$ and $p^{A}$ are marketable, we can clearly see from (2) that arbitrageurs supply state $s$ consumption to exchange $k$ when the price that agents on $k$ are willing to pay,

\footnotetext{
${ }^{7}$ This can be seen directly from equation (12) in the proof of Lemma 3.1 in the Appendix.
} 
$p^{k}(s)$, exceeds the arbitrageurs' own valuation, $p^{A}(s) .{ }^{8}$ This statement should be qualified, since while these are the "optimal" supplies in some sense (to be confirmed subsequently), they may not be marketable, i.e. they may not be implementable via a portfolio of the existing securities. Therefore, arbitrageurs will supply state $s$ consumption to exchange $k$ if the marketable component of the excess willingness to pay, $\left(p^{k}-p^{A}\right)_{M^{k}}=p_{M^{k}}^{k}-p_{M^{k}}^{A}$, is positive in state $s$.

The factor of proportionality in (2) is determined by two considerations. First, the deeper is exchange $k$ (i.e. the lower is $\beta^{k}$ ), the more arbitrageur $n$ trades on this exchange, since he can afford to augment his supply without affecting margins as much. And second, the supply vector is scaled to zero as competition intensifies, because the whole pie shrinks and there are more players to share the smaller pie with (see also Lemma 3.4 below).

Note that generically all arbitrageurs trade across all exchanges (provided there are arbitrage opportunities). In particular, arbitrageurs never carve up the set of exchanges amongst themselves with a view to reducing competition.

Lemma 3.2 gives us the equilibrium supply $y^{k, n}$ of arbitrageur $n$. The total equilibrium supply is then $y^{k}=N y^{k, n}$. Substituting into the pricing equation (1) determines the equilibrium prices:

Lemma 3.3 (Equilibrium prices) The following is an equilibrium state-price deflator for exchange $k$ :

$$
\hat{p}^{k}=\frac{1}{1+N} p^{k}+\frac{N}{1+N} p^{A} .
$$

In particular, as $N$ goes to infinity, the equilibrium valuation on each exchange converges to the arbitrageurs' valuation: $\lim _{N \rightarrow \infty} \hat{p}^{k}=p^{A}$.

Intuitively, in equilibrium, prices on exchange $k$ reflect in a convex fashion both the marginal valuation of the investors on $k$ after having exhausted all gains from trade amongst themselves, $p^{k}$, as well as the marginal valuation of the arbitrageurs, $p^{A}$. For $N=0$, equilibrium state prices are equal to autarky state prices: $\hat{p}^{k}=p^{k}$. As $N \rightarrow \infty$, the equilibrium state-price deflator converges to the arbitrageur's marginal valuation. The arbitrageurs' valuation in turn does not depend on $k$, but rather depends globally on the marginal valuations of all exchanges.

Finally, we calculate the equilibrium profits of arbitrageur $n$ (which do not depend on $n$ since the CWE is symmetric), $\Phi:=\sum_{k} q^{k} \cdot y^{k, n}$.

Lemma 3.4 (Equilibrium profits) The equilibrium profits of an arbitrageur, for given asset structure $\left\{d^{k}\right\}_{k \in K}$, are given by

$$
\Phi\left(\left\{d^{k}\right\}\right)=\frac{1}{(1+N)^{2}} \cdot \sum_{k} \frac{1}{\beta^{k}} E\left[\left(p_{M^{k}}^{k}-p_{M^{k}}^{A}\right)^{2}\right] .
$$

\footnotetext{
${ }^{8}$ Assume for instance that there are three exchanges, with complete markets on each exchange, and that $p^{1}(s)<p^{2}(s)<p^{3}(s)$. We will show later (Lemmas 4.1 and 4.2 ) that $p^{A}$ is a convex combination of the $p^{k}$ 's. Then, from Lemma 3.2, arbitrageurs necessarily buy state $s$ consumption on exchange 1 and sell on exchange 3 . They may buy or sell on exchange 2 ; they buy on 2 if and only if $p^{2}(s)<p^{A}(s)$.
} 
A typical arbitrageur's equilibrium profits are equal to the sum across exchanges of the size of (the marketable component of) the difference between the marginal investors' willingness to pay in autarky and the arbitrageur's shadow value, scaled down by shallowness and by the degree of competition. As $N$ goes to infinity, individual arbitrageur trades vanish, as do total arbitrageur profits $N \Phi$. The vanishing of aggregate arbitrageur profits as $N$ increases without bound suggests that the arbitrageurs perform the duties of a Walrasian auctioneer in the limiting equilibrium.

\section{A Walrasian Benchmark}

It turns out that the equilibrium of the arbitraged economy that we have just computed bears a close relationship to an appropriately defined competitive equilibrium, with no arbitrageurs. This relationship is somewhat subtle, however. The reader is referred to Rahi and Zigrand (2007b) for an analysis of the general case. In this section we restrict ourselves to asset structures that satisfy a certain spanning condition which holds at the equilibrium security design and also suffices for our welfare results. Under this spanning condition, we show that arbitrageur valuations and Walrasian valuations coincide.

Let $p^{*}$ denote the complete-markets Walrasian state-price deflator of the entire integrated economy with no participation constraints. We have:

Lemma 4.1 (Walrasian benchmark) The complete-markets Walrasian state-price deflator $p^{*}$ is given by

$$
p^{*}=\sum_{k \in K} \lambda^{k} p^{k}
$$

where

$$
\lambda^{k}:=\frac{\frac{1}{\beta^{k}}}{\sum_{j=1}^{K} \frac{1}{\beta^{j}}}, \quad k \in K
$$

and the complete-markets Walrasian net trades between exchanges are

$$
\frac{1}{\beta^{k}}\left(p^{k}-p^{*}\right), \quad k \in K
$$

Furthermore, $p^{*}=1-\beta \omega \geq 0$.

The state-price deflator $p^{*}$ reflects the investors' economy-wide average willingness to pay, with the willingness to pay on each exchange weighted by its relative depth.

We can now state the spanning condition alluded to above:

(S) Either (a) $d^{k}=d, k \in K$, or (b) $p^{k}-p^{*} \in M^{k}, k \in K$.

Under $\mathbf{S}($ a) we have an standard incomplete markets economy in which all investors can trade the same set of assets. $\mathbf{S}(\mathrm{b})$ is the condition that characterizes an equilibrium security design, as we shall see in the next section. 
Lemma 4.2 (Arbitrageur valuations) Under $\mathbf{S}$, arbitrageur valuations in the CWE coincide with valuations in the complete-markets Walrasian equilibrium, i.e. we can choose $p^{A}=p^{*}$.

We showed in Lemma 3.3 that the state-price deflator $\hat{p}^{k}$ converges to $p^{A}$ as the number of arbitrageurs grows without bound. Hence we have:

Proposition 4.1 (Convergence to Walrasian equilibrium) Suppose the asset structure satisfies condition $\mathbf{S}$. Then the equilibrium valuation on exchange $k$ in the arbitraged economy converges to the complete-markets Walrasian equilibrium valuation as the number of arbitrageurs $N$ goes to infinity, i.e. $\lim _{N \rightarrow \infty} \hat{p}^{k}=p^{*}$.

Thus asset prices in the arbitraged economy converge to asset prices in the completemarkets Walrasian equilibrium: $\lim _{N \rightarrow \infty} q^{k}=E\left[d^{k} p^{*}\right]$. It is in this sense that arbitrageurs serve to integrate markets.

It should be noted that, as $N$ goes to infinity, we get convergence to the completemarkets Walrasian equilibrium valuation (under $\mathbf{S}$ ). In general, however, we do not get convergence to the complete-markets Walrasian equilibrium allocation. ${ }^{9}$ A sufficient condition for the latter is complete markets on each exchange. As we shall see later (Proposition 6.1), $\mathbf{S}(\mathrm{b})$ suffices as well if investors are identical within each exchange.

Proposition 4.1 can be viewed as a formal statement of the often-heard comment that the current proliferation of arbitrage hedge funds leads to more efficient markets. However, in view of Lemma 3.4, these funds cannot be viewed as an asset class by themselves (like equities and bonds, for example) since a higher number of funds leads to lower fund returns, both individually and in the aggregate, converging to zero in the limit.

\section{$5 \quad$ Security Design by Arbitrageurs}

We have seen that there is a unique CWE associated with any asset structure $\left\{d^{k}\right\}_{k \in K}$. In this section we endogenize the security payoffs.

Arbitrageurs play the following security design game. Each arbitrageur introduces securities on each exchange, which are then traded by all arbitrageurs. Formally, arbitrageur $n$ chooses security payoffs $\left\{d^{k, n}\right\}_{k \in K}$. Given a strategy profile $\left\{d^{k, n}\right\}_{k \in K, n \in N}$, the asset structure for the economy is $\left\{d^{k}\right\}_{k \in K}$, where $d^{k}=\cup_{n \in N} d^{k, n}$ (here union has the obvious meaning: an asset is in $d^{k}$ if and only if it is in $d^{k, n}$, for some $n$ ). The payoffs of arbitrageurs are the profits they earn in the CWE associated with this asset structure. Due to symmetry of the trading game, all arbitrageurs have the same payoff. We say that an asset structure $\left\{d^{k}\right\}_{k \in K}$ is a Nash equilibrium of the security design game if $d^{k}=\cup_{n \in N} d^{k, n}$, all $k$, for some Nash equilibrium profile

\footnotetext{
${ }^{9}$ Under $\mathbf{S}$, the allocation converges to the restricted-participation Walrasian equilibrium allocation; see Rahi and Zigrand (2007b) for details.
} 
$\left\{d^{k, n}\right\}_{k \in K, n \in N}$. An asset structure is optimal for arbitrageurs if it yields the highest payoff for arbitrageurs, among all possible asset structures.

Proposition 5.1 The following statements are equivalent:

1. $p^{k}-p^{*} \in\left\langle d^{k}\right\rangle$, for all $k \in K$;

2. the asset structure $\left\{d^{k}\right\}_{k \in K}$ is optimal for arbitrageurs;

3. the asset structure $\left\{d^{k}\right\}_{k \in K}$ is a Nash equilibrium of the security design game.

Thus the complete asset structure, with complete markets on every exchange, is optimal for arbitrageurs, and a Nash equilibrium. Given the complexity of the real world, this would require a very large number of securities. However, all optimal/equilibrium asset structures are payoff-equivalent for arbitrageurs. Among these, a minimal asset structure is one with the smallest number of assets. Such an asset structure would be the one chosen if each security issued bore a fixed cost $c$, no matter how small. ${ }^{10}$ Our main security design result is an immediate consequence of Proposition 5.1: ${ }^{11}$

Proposition 5.2 (Security design) The asset structure

$$
d^{k}=p^{k}-p^{*}, \quad k \in K
$$

$i s$

1. the unique minimal optimal asset structure for arbitrageurs; and

2. the unique minimal Nash equilibrium of the security design game.

The optimal asset structure for arbitrageurs spans the net trades between exchanges in the complete-markets Walrasian equilibrium, which are given by (5). The minimal optimal security, and the unique minimal equilibrium, on exchange $k$ is a swap, exchanging the autarky state-price deflator of exchange $k$ for the completemarkets Walrasian state-price deflator of the entire integrated economy. If there are only two exchanges, say 1 and 2 , then the optimal securities $p^{1}-p^{*}$ and $p^{2}-p^{*}$ are both proportional to $p^{1}-p^{2}$, the difference of the autarky state-price deflators of the two exchanges.

A reading of the optimal arbitrage supply $d^{k} \cdot y^{k, n}$, which is proportional to $p_{M^{k}}^{k}-p_{M^{k}}^{A}$ (from Lemma 3.2), suggests that the optimal security design for arbitrageurs should be as given in the proposition. When arbitrageurs must operate with exogenously given assets, they supply state-contingent consumption to exchange $k$ that is (up to a scalar multiple) as close as possible to $p^{k}-p^{A}$ using the given assets, i.e. $p_{M^{k}}^{k}-p_{M^{k}}^{A}$. If now they can design securities, they can supply exactly $p^{k}-p^{A}$

\footnotetext{
${ }^{10}$ In fact, such fixed costs are significant; see Tufano (1989) for an empirical assessment.

${ }^{11}$ When we say "unique", we mean "unique up to scaling."
} 
rather than the best approximation of $p^{k}-p^{A}$. Moreover, under this security design, $p^{A}=p^{*}$ from Lemma 4.2. A notable feature of the equilibrium asset structure is that it allows arbitrageurs to run what practitioners call a "matched book," i.e. an asset position with exactly offsetting future payoffs.

Note that a single security on each exchange suffices for arbitrageurs to maximize their profits, and our result therefore generates incomplete markets endogenously, without any constraint on the number of securities. The reason is that, within any exchange $k$, asset prices are determined by a Walrasian auction and arbitrageurs do not profit from those intra-exchange trades. Intuitively, arbitrageurs only profit from mispricings between the market price of the innovation and the replicating portfolio. They are therefore only concerned with the one-dimensional net trade they mediate between $k$ and the rest of the economy, which can be accomplished via a single security collinear with the desired net trade. Relatedly, if $p^{k}=p^{*}$, we claim that arbitrageurs do not find it profitable to introduce any assets on exchange $k$. But isn't it true that, with heterogeneous investors on exchange $k$, there must be some agent willing to pay or receive an amount different from the one on some other exchange, and therefore provide an incentive to innovate? The answer is no, since if such an asset is sold to investor $(k, i)$, all other agents on $k$ can trade that same asset as well, by nonexclusivity. The resulting price established on exchange $k$ is such that no arbitrage opportunities arise across exchanges: $p^{k}=p^{*}$.

Finally, it is interesting to realize that although net trades, and therefore equilibrium allocations, depend on the degree of competition $N$, the equilibrium asset structure does not depend on $N$. This is a feature of the linear-quadratic model in which demand functions are linear, and depth is a constant independent of trading volume. We discuss this further in the next section.

Our analysis readily extends to the more realistic case where arbitrageurs can innovate on all exchanges, but there are pre-existing assets whose payoffs $\left\{d^{k}\right\}$ they cannot affect. In other words, security design really represents incremental innovation. For instance, if there is some exchange $k$ which has complete markets, one can interpret the result as the optimal design of redundant derivative securities on the other exchanges. The following result is immediate from Proposition 5.1.

Proposition 5.3 (Innovation) For given $\left\{d^{k}\right\}_{k \in K}$, the asset structure

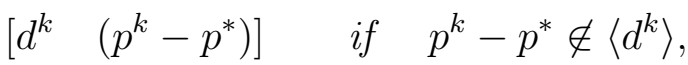

$$
\begin{aligned}
& d^{k} \quad \text { if } \quad p^{k}-p^{*} \in\left\langle d^{k}\right\rangle \text {, }
\end{aligned}
$$

$i s$

1. a minimal optimal asset structure for arbitrageurs; and

2. a minimal Nash equilibrium of the security design game.

Since for a given $\left\{d^{k}\right\}$ arbitrageurs find it optimal to supply state-contingent consumption proportional to $p^{k}-p^{*}$ if allowed, they innovate on exchange $k$ if and 
only if $p^{k}-p^{*} \notin\left\langle d^{k}\right\rangle$, in which case they "complete" the market by adding $p^{k}-p^{*}$. Equivalently, they could add a security that makes $p^{k}-p^{*}$ tradable in conjunction with $d^{k}$. For this reason, we can no longer say that $\left[d^{k}\left(p^{k}-p^{*}\right)\right]$ is the unique minimal asset structure.

Example 1 (Property Total Return Swaps) Recall, from our discussion in the Introduction, that a TRS swaps the rate of return on a property index with a prespecified interest rate. We show how our framework can generate a TRS as an equilibrium security.

Assume that in terms of property exposure the market can be split into $K \geq 2$ clienteles. Clientele 1 represents investors who are endowed with a given type of commercial property $\hat{\omega}$. The remaining clienteles initially have no exposure to such commercial property but would like to diversify into it. Let us also assume for simplicity that all clienteles are reasonably diversified with respect to all other sectors, $\check{\omega}$, with clientele $k$ owning a fraction $\phi^{k}$ of the global aggregate holdings. We can view the non-property sector to be a global equity index for concreteness. Then the endowments are $\omega^{1}=\hat{\omega}+\phi^{1} \check{\omega}$ and $\omega^{k}=\phi^{k} \check{\omega}, k \geq 2$. The (not necessarily marketable) global market portfolio is therefore $\omega=\sum_{k=1}^{K} \omega^{k}=\hat{\omega}+\check{\omega}$.

Using the fact that $p^{*}=1-\beta \omega$, the equilibrium security on exchange 1 is $p^{1}-p^{*}=\left(\beta-\beta^{1}\right) \hat{\omega}+\left(\beta-\beta^{1} \phi^{1}\right) \check{\omega}$. Similarly, the equilibrium security introduced on exchange $k \neq 1$ is $p^{k}-p^{*}=\beta \hat{\omega}+\left(\beta-\beta^{k} \phi^{k}\right) \check{\omega}$. If all clienteles already have access to the global equity index through their local exchanges $\left(\check{\omega} \in\left\langle d^{k}\right\rangle\right.$, all $k \in K$ ), then, from Proposition 5.3, the same security $\hat{\omega}$ marketed to each clientele is a minimal equilibrium security design.

This security is simply a claim to the property $\hat{\omega}$. Let us denote its equilibrium date 0 price by $q$. If there is a global risk free asset with rate $r$, the equilibrium security can equivalently be represented by the time 1 payoff $\hat{\omega}-(1+r) q$. This is exactly the payoff of a TRS. Just as in the real world, the contract swaps the economic interest in the underlying property but allows clientele 1 to remain the owner and to continue to enjoy the non-economic convenience yield of the property, if any.

Example 2 (Survivor Swaps, a.k.a. Mortality Swaps) Defined benefit pension plans and annuity providers are naturally long longevity risk, while life insurers, pharmaceutical companies and long term care homes are naturally short longevity risk. Survivor swaps (as described for instance in Dowd et al. (2006)) are intermediated by banks, in which the preset-rate leg is linked to a published mortality projection, and the floating leg is linked to realized mortality. The attractions of these arrangements are the obvious ones of risk mitigation and capital release for those laying off mortality risk, and good risk diversification due to low comovement with the overall market for those taking it on. 


\section{$6 \quad$ Security Design and Social Welfare}

For each asset structure $\left\{d^{k}\right\}_{k \in K}$, there is a unique CWE with the corresponding equilibrium payoffs for each arbitrageur and investor. In this section we do a welfare comparison of alternative asset structures by comparing the equilibrium payoffs associated with them. We say that an asset structure is socially optimal if it is Pareto optimal for the set of all agents, arbitrageurs and investors.

Equilibrium arbitrageur profits are given by Lemma 3.4. Equilibrium utilities of investors are as follows:

Lemma 6.1 (Equilibrium utilities) The equilibrium utility of investor $(k, i)$, for given asset structure $\left\{d^{k}\right\}_{k \in K}$, is (an affine function of)

$$
W^{k, i}:=\beta^{k, i} E\left[\left(d^{k} \cdot \theta^{k, i}\right)^{2}\right]=\frac{1}{\beta^{k, i}} E\left[\left(\left(p_{M^{k}}^{k, i}-p_{M^{k}}^{k}\right)+\frac{N}{1+N}\left(p_{M^{k}}^{k}-p_{M^{k}}^{A}\right)^{2}\right] .\right.
$$

Note that $W^{k, i}$ is a particular affine transformation of $U^{k, i}$, being equal to zero when the agent does not trade. Quite intuitively, the utility gains from trade are higher (roughly speaking) the greater is the difference between an investor's no-trade valuation and the autarky valuation of his exchange, on the one hand, and the greater is the difference between the autarky valuation of his exchange and the economy-wide valuation $p^{A}$, on the other.

We say that investors on exchange $k$ are homogeneous if they have the same no-trade valuations, i.e. $p^{k, i}=p^{k}$, for all $i \in I^{k}$. We refer to an economy in which investors are homogeneous within each exchange as a clientele economy. From the point of view of arbitrageurs, each clientele $k \in K$ consists of agents with identical characteristics.

We will focus now on a clientele economy, returning to the general heterogeneous agent case at the end of the section. Lemma 6.1 gives us the following welfare index for clientele $k$ :

$$
W^{k}:=\sum_{i \in I^{k}} W^{k, i}=\frac{1}{\beta^{k}}\left(\frac{N}{1+N}\right)^{2} E\left[\left(p_{M^{k}}^{k}-p_{M^{k}}^{A}\right)^{2}\right] .
$$

Comparing this to (4), we see that the egalitarian social welfare function $\sum_{k} W^{k}$ is proportional to arbitrageur profits $\Phi$. Hence an asset structure that maximizes arbitrageur profits is in fact socially optimal: ${ }^{12}$

\footnotetext{
${ }^{12}$ This result has been foreshadowed by Postlethwayt (1757) who states in his entry on arbitrage that "It does not always fall out, that the interest of private traders coincides with that of the nation in general; but in the present case, it does: for while our merchants of ingenuity are gaining advantages by themselves, by their skills in the exchanges, they necessarily contribute to rule and control the courses of exchange in general, more and more in favor of our country than otherwise they could be."
} 
Proposition 6.1 (Optimality: clientele economy) In a clientele economy, an optimal asset structure for arbitrageurs (which is also a Nash equilibrium of the security design game) is socially optimal.

This is not surprising given that the optimal arbitrageur-chosen securities span the net trades between exchanges in the complete-markets Walrasian equilibrium of the integrated economy. Consider the minimal equilibrium security design $\left\{p^{k}-p^{*}\right\}$. The intuitive reason why $p^{k}-p^{*}$ is the right asset for exchange $k$ is diversification. Let $\theta^{k}:=\sum_{i \in I^{k}} \theta^{k, i}$ be the aggregate portfolio of exchange $k$, which in equilibrium is equal to the aggregate arbitrageur supply $y^{k}$. From Lemma 3.2, exchange $k$ receives state-contingent consumption equal to

$$
\begin{aligned}
d^{k} \cdot y^{k} & =\frac{N}{(1+N) \beta^{k}}\left(p^{k}-p^{*}\right) \\
& =\frac{N}{1+N}\left(\frac{\beta}{\beta^{k}} \omega-\omega^{k}\right)
\end{aligned}
$$

where we recall that $p^{k}:=1-\beta^{k} \omega^{k}$, and $p^{*}=1-\beta \omega$ by Lemma 4.1. Thus investors on exchange $k$ get rid of their idiosyncratic risk $\omega^{k}$ and acquire a proportional position in the global undiversifiable market portfolio $\omega$, with a constant of proportionality that depends on their relative level of risk tolerance.

Another way to see why the security $p^{k}-p^{*}$ is optimal for clientele $k$ is the following. From Lemma 3.3, $p^{k}-p^{*}$ is collinear with $\hat{p}^{k}-\hat{p}^{\lambda}$, where $\hat{p}^{\lambda}:=\sum_{j \in K} \lambda^{j} \hat{p}^{j}$. In general, it is well-known (see Magill and Quinzii (1996)) that the state-price deflator evaluated at an equilibrium is locally the most valued security for an agent. In our case, this is $\hat{p}^{k}$ for clientele $k$. The optimal security for clientele $k$ allows agents in this group to obtain the payoffs of their most valued security $\hat{p}^{k}$, while shorting the payoffs of the most valued securities of other clienteles $\left\{\hat{p}^{j}\right\}_{j \neq k}$. In equilibrium, agents are induced to hold the swap by prices and by the underlying motivation to diversify. It is a consequence of our linear-quadratic formulation that the optimal asset structure at the arbitraged equilibrium, namely $\left\{\hat{p}^{k}-\hat{p}^{\lambda}\right\}$, is the same as the optimal asset structure at the autarky equilibrium, $\left\{p^{k}-p^{*}\right\}$. Thus the optimal security design in the arbitraged economy depends only on the autarky equilibrium and not on the amount supplied by arbitrageurs.

However, while the equilibrium securities correspond to socially desirable ones, the allocation that results is not Pareto optimal; it is merely Pareto-undominated within the class of CWE allocations for different asset structures. Arbitrageurs are strategic and restrict their asset supplies in order to benefit from the markup. This implies that not all gains from trade are exhausted. We can see this by comparing the net trades in the complete-markets Walrasian equilibrium, given by (5), and the net trades at the CWE, given by (7). The latter trades are lower by a factor $N /(1+N)$ due to imperfect competition. For $N=0$, no consumption can be intermediated since there are no intermediaries. More diversification is achieved as $N$ increases, but it is only when $N$ tends to infinity that equilibrium allocations converge to Walrasian allocations, and therefore to a Pareto optimum. 
A socially optimal asset structure is not necessarily optimal for each clientele. For example, starting from an initial asset structure $\left\{d^{k}\right\}$, if markets are completed for each clientele, the resulting security design is socially optimal. However, some clienteles may be worse off since prices are typically affected by the introduction of new securities and lead to redistributions. This possibility has been discussed by Elul (1999), for instance. The following proposition addresses the important question as to who gains and who loses as a result of an optimal financial innovation, and what the drivers are.

Proposition 6.2 (Welfare gains and losses) In a clientele economy with initial asset structure $\left\{d^{k}\right\}_{k \in K}$, clientele $k$ is worse off at a socially optimal asset structure if and only if

$$
E\left[\left(p^{k}-p^{*}\right)^{2}\right]<E\left[\left(p_{M^{k}}^{k}-p_{M^{k}}^{A}\right)^{2}\right] .
$$

This follows directly from (6). Clientele $k$ is worse off if and only if the total marketable gains from trade are smaller after the innovation than before.

Example 3 Consider an economy consisting of three exchanges, 1, 2 and 3, with a single agent on each exchange. There are two states, $S=\{1,2\}$, with $\pi_{1}$ and $\pi_{2}$ the probabilities of states 1 and 2 respectively. Asset payoffs are as follows. Exchange 1 has one security paying off 1 if state 1 obtains, and nothing if state 2 obtains. Exchange 2 trades a riskless bond paying 1 in both states. Exchange 3 has a complete set of Arrow securities, Arrow security $s$ paying 1 if and only if state $s$ occurs. Exchanges 1 and 2 are equally deep, with $\beta^{1}$ and $\beta^{2}$ both equal to $\bar{\beta}$, which satisfies

$$
0<\bar{\beta}<\frac{\pi_{1}}{1+\pi_{1}} .
$$

Date one endowments are deterministic and given by $\omega^{1}=1, \omega^{2}=1 / \bar{\beta}-1$ and $\omega^{3}=1 /\left(2 \beta^{3}\right)$. Autarky state-price deflators are, therefore, $p^{1}=1-\bar{\beta}, p^{2}=\bar{\beta}$ and $p^{3}=1 / 2$, respectively. Exchange 1 values time one consumption more than exchange 2. In autarky, $q^{1}=(1-\bar{\beta}) \pi_{1}, q^{2}=\bar{\beta}$ and $q^{3}=\left(\pi_{1} / 2, \pi_{2} / 2\right)$.

The restriction (8) implies that $q^{1}>q^{2}$, i.e. there exist profit opportunities for arbitrageurs, buying on exchange 2 and delivering to exchange 1 . It is also easy to check that $p^{3}=p^{*}$, the complete markets Walrasian state-price deflator. While there may be many arbitrage opportunities, including some involving exchange 3 , the parameters chosen ensure that $p^{2}<p^{3}<p^{1}$, so that the main opportunity lies in going long on exchange 2 and going short on exchange 1, while using exchange 3 merely to lay off the excess consumption in state 2 that results from this arbitrage trade. Exchange 3 is not principally used because of its mispriced securities, but serves as a passive financing exchange.

Under the optimal security design $d^{k}=p^{k}-p^{*}$, or equivalently a complete set of Arrow securities on each exchange, the arbitrageurs' shadow valuation is $p^{*}$, which coincides with exchange 3's valuation. As a result, there is no trade on 3. Arbitrageurs simply buy on 2 and deliver to 1, no longer relying on 3 for financing. On 
the other hand, under the given initial asset structure, the arbitrageurs' shadow valuation $p^{A}$ satisfies $p^{3}-p^{A}=p_{M^{3}}^{3}-p_{M^{3}}^{A} \neq 0$, provided $\beta^{3}$ is sufficiently small. ${ }^{13}$ Hence there is trade on exchange 3 prior to the innovation, and welfare is higher on this exchange than under the optimal security design.

The example shows that not every exchange may benefit when all exchanges are completed because the completion of markets may erode the advantages an exchange may have had before the completion. Exchange 3 plays a valuable role in the arbitrage process at the initial asset structure, facilitating trade between the other two exchanges. At a socially optimal asset structure, however, it becomes entirely superfluous. This is reminiscent of what was also found in Willen (2005). We can similarly show that when no clientele initially enjoys a trading advantage, then all clienteles benefit from optimal security design.

Proposition 6.3 (Pareto-improving security design) Consider a clientele economy, with an initial asset structure that satisfies $\mathbf{S}$. Then no clientele can be worse off at a socially optimal asset structure.

Condition $\mathbf{S}(\mathrm{b})$ means that the initial asset structure is already socially optimal. In the case of common payoff matrices, condition $\mathbf{S}(\mathrm{a})$, no exchange is at a trading advantage at the initial equilibrium as trades that can be executed on one exchange can equally be carried out on some other exchange.

Note that, in going from an initial asset structure to a socially optimal one, we allow for the possibility of removing some of the initial assets. When we restrict attention to innovation (not necessarily optimal) of additional assets, Proposition 6.3 extends to the general case where agents may be heterogeneous within exchanges.

Proposition 6.4 (Pareto-improving innovation) Suppose arbitrageurs introduce new assets, and $\mathbf{S}$ is satisfied at both the initial and the post-innovation asset structure. Then no investor can be worse off after the innovation.

In particular, starting from a common asset structure $d^{k}=d$, all $k$, if arbitrageurs innovate optimally (i.e. the post-innovation asset structure satisfies $\mathbf{S}(\mathrm{b})$ ), all agents are better off. Even though arbitrageurs are solely interested in their own profits, in this case maximal profit extraction means providing each investor with his favorite assets.

The intuition for Proposition 6.4 is clearest in the limiting equilibrium as $N$ goes to infinity. We know from Proposition 4.1 that the complete-markets Walrasian state-price deflator applies in this equilibrium. With quadratic preferences, adding

\footnotetext{
${ }^{13} \mathrm{~A}$ straightforward but tedious derivation shows that $p^{A}(1)=\frac{\frac{1}{2}-\lambda^{1}+\left(\lambda^{1}\right)^{2} \pi_{2}(1-\bar{\beta})}{1-2 \lambda^{1}+\left(\lambda^{1}\right)^{2} \pi_{2}}$ and $p^{A}(2)=\frac{\frac{1}{2}-\lambda^{1}(3 / 2-\bar{\beta})+\left(\lambda^{1}\right)^{2} \pi_{2}(1-\bar{\beta})}{1-2 \lambda^{1}+\left(\lambda^{1}\right)^{2} \pi_{2}}$, both of which are nonnegative provided $\beta^{3} \leq$ $\frac{2 \bar{\beta}^{2}+\bar{\beta}+\sqrt{4 \bar{\beta}^{4}-\left(4+8 \pi_{1}\right) \bar{\beta}^{3}+8 \pi_{1} \bar{\beta}^{2}+2 \bar{\beta}}}{4\left(\pi_{1}-\bar{\beta}\left(1+\pi_{1}\right)\right)}$. The deflator $p^{A}$ can be obtained more easily by exploiting the general results in Rahi and Zigrand (2007b).
} 
assets leaves the state-price deflator unchanged. Innovation cannot hurt investors as it does not affect the prices of the initial assets. It should be noted, however, that we do require that both the pre- and post-innovation asset structures satisfy $\mathbf{S}$. This is the case, for example, when agents have access to the same asset markets before and after the innovation. In Example 3, $\mathbf{S}$ was not satisfied at the initial equilibrium, and we saw that completing markets on all exchanges moved prices unfavorably for some agents.

These results should be contrasted with those in Willen (2005) and Acharya and Bisin (2006). These papers use a CARA-Gaussian setting, in which introducing a new asset does not affect the prices of the risky assets that are already being traded. Adding an asset is therefore always welfare-improving, provided there is no consumption at the initial date. With consumption at both dates, and with the riskfree asset available for trade, adding an asset increases the risk-free interest rate, so that agents who are net borrowers may be worse off. This is the only channel through which financial innovation can hurt agents. We should also point out that some of the welfare results in Willen (2005) and all of those in Acharya and Bisin (2006) use a welfare measure involving lumpsum transfers, while we follow the more standard approach of using the Pareto criterion.

Proposition 6.1 does not extend to the heterogeneous agent case. The minimal equilibrium security design $\left\{p^{k}-p^{*}\right\}$ will in general be Pareto dominated by complete markets on every exchange. In a clientele economy both these asset structures are socially optimal, and indeed payoff-equivalent for every investor and arbitrageur. This is not so with heterogeneous agents. If there is sufficient heterogeneity, with $I^{k}>S$ distinct investors on each exchange $k$, there will typically be $S$ linearly independent optimal net trades on every exchange, so that the only socially optimal asset structure is the the one with complete markets on all exchanges.

The reason why the security design $\left\{p^{k}-p^{*}\right\}$ fails to be socially optimal is because arbitrageurs only care about aggregate valuations on the various exchanges. They do not consider the effects of their security choice on the intra-exchange reallocation of resources that occurs when investors on a given exchange trade the security among themselves. Such intra-exchange trades are absent in a clientele economy $\left(p^{k, i}=p^{k}\right.$, all $k$ ), which is why profit maximization by arbitrageurs is socially efficient in that case.

\section{Macro Markets}

Robert Shiller (see Shiller (1993)) has argued that one of the most important categories of missing markets are markets for country GDP, which he calls "macro markets." Stock markets for instance allow investors to trade only the small component of national income that corresponds to corporate profits.

Since each trade needs a counterparty, macro markets can only be successful if there is both a demand and a supply for a claim on each country's GDP stream, not least because otherwise innovators would not choose to launch such products. 
Demand and supply must naturally be international. In that spirit, we proceed to study macro markets within our formal model, reinterpreting exchanges as countries.

Assume initially that there are two countries, $k=1,2$. We have seen that arbitrageurs would find it optimal to introduce one single (further) asset in country $k, p^{k}-p^{*}$, which in this simple example means a payoff collinear with $\left(\beta^{1} \omega^{1}-\beta^{2} \omega^{2}\right)$. Since $\omega^{k}$ amounts in fact to GDP in country $k$, the equilibrium security corresponds to the depth-weighted difference of the GDPs in the two countries.

An asset structure $d^{1}=d^{2}=\left(\omega^{1}, \omega^{2}\right)$ would also be an equilibrium of the design game, albeit not a minimal one. What does come out of this, though, is that introducing country $k$ 's GDP as a tradable asset in country $k$ only is optimal neither for arbitrageurs nor for investors. Investors in country $k$ want to be able to simultaneously sell a portion of their GDP and diversify their portfolios by buying a fraction of world GDP.

With $K$ arbitrary, arbitrageurs could therefore introduce claims to the GDP of each and every country in all countries. But it is more reasonable and cheaper to introduce only the ideal security in country $k$, which is the difference of the GDP outcomes of country $k$ with the rest of the world, properly weighted by depth.

With this caveat, Shiller's conjecture as to the importance of GDP markets is mirrored in our model: those are indeed the equilibrium assets designed and traded by profit-maximizing innovative institutions. Nevertheless, while macro GDP markets are optimal for arbitrageurs, Proposition 6.2 should caution us as to their social welfare properties. Shiller has not specified any particular social welfare function, and therefore claims must be evaluated carefully. Even with homogeneous investors within each country, some countries may lose out from the introduction of macro markets, especially those that provide substitute insurance. Realistically, these countries may also be the ones with the greatest political influence to prevent macro markets.

Finally, while Shiller's conjecture does yield a social optimum with homogeneous investors within each country, this is no longer true when they are heterogeneous. Even though macro markets are the ones that innovators will in fact establish, on their own they are not socially efficient in general.

\section{Relationship to the Literature}

This paper lies at the intersection of two distinct literatures - the literature on security design and that on segmented markets. Research on security design in an incomplete markets framework is surveyed in Allen and Gale (1994) and Duffie and Rahi (1995). A number of papers study security design in a two-period mean-variance setting. Of particular relevance to the present paper are Demange and Laroque (1995), Rahi (1995), Willen (2005), and Acharya and Bisin (2006). ${ }^{14}$ The canonical

\footnotetext{
${ }^{14}$ All of these papers assume CARA utility and normal distributions (Demange and Laroque (1995) contains some general results as well). We do not follow this route since nonnegativity restrictions on arbitrageurs' final wealth are a key feature of our analysis and this makes the use of normal distributions problematic. Willen (2005) and Acharya and Bisin (2006) are also discussed
} 
problem posed in these papers is that of characterizing the optimal set of assets, given an exogenous bound on the number of assets. The optimal assets are maximal eigenvectors of a suitably defined matrix that depends on the endowments of all the agents. Similar results are obtained in the literature on exchange-driven innovation (e.g. Duffie and Jackson (1989) and Cuny (1993)). This class of security design results is very different from those that we report in this paper. In particular, these models cannot account for the innovation of redundant assets.

In a model of securitization of an issuer's assets, in which investors face short sales restrictions, Allen and Gale (1988) obtain a security design that is superficially similar to ours in that the securities innovated are redundant and marketed to various clienteles. In other respects, however, their characterization of "extremal" securities is completely different from ours, and is not generated by issuers catering to unspanned risks. Indeed, the economy-wide asset structure is exogenously given in their model and the securities issued are redundant by assumption.

DeMarzo and Duffie (1999) and DeMarzo (2005) offer an explanation of the pooling and tranching of securities in a setup with risk neutral agents and privately informed issuers. Our framework, while not specifically designed to study asset-backed securitization, delivers a complementary explanation, driven by market incompleteness and participation constraints, of intermediaries buying securities from some investors, and then using these as "collateral" to sell securities to various clienteles.

The segmented markets framework that we employ in this paper is adapted from Zigrand $(2004,2006)$ where the asset structure is taken to be exogenous. That not all asset prices are determined simultaneously by the same marginal perfectly diversified investor would be considered an axiom by practitioners. It has also been the basis of early academic research, particularly in fixed income - see the market segmentation hypothesis posited by Culbertson (1957) or the preferred habitat hypothesis of Modigliani and Sutch (1966). However, it is only recently that a series of papers have tried to empirically quantify the extent to which state prices differ across markets. One of the first systematic studies is the paper by Chen and Knez (1995). They find that the NYSE and NASDAQ are priced by sets of state prices which are close in mean-squared distance but do not intersect, showing that the marginal investors on the two markets are close but distinct. There is also a prolific literature on the international APT as well as on home bias, wherein a national stock market is held and priced predominantly by national investors (see Lewis (1999) for a survey). More recently, there have been a number of event studies of changes in the composition of the S\&P 500 index (see for instance Massa et al. (2005)). Around the time of the addition a stock to the index, mutual funds benchmarked to the index have an incentive to purchase the stock, and their marginal valuations are shown to differ from those of the market at large. Part of the resulting arbitrage is in fact performed by the managers of the company admitted to the index. Similarly, Da and Gao (2006) provide empirical evidence supporting the view that a sharp rise in a firm's default likelihood causes a change in its shareholder clientele as mutual funds decrease their

in Section 6. 
holdings of the firm's shares. This liquidity shock is initially absorbed by marketmakers before large traders move in to provide the liquidity. Gabaix et al. (2007), in a study of the mortgage-backed securities (MBS) market, show that collateralized mortgage obligations (CMOs) are priced not by the marginal investor of the broader market whose state prices depend on the aggregate wealth of the economy, but by investors wholly specialized in the MBS market. The intermediaries who purchase the mortgages and transform them into CMOs play the role of our arbitrageurs. Finally, Blackburn et al. (2006) find that the marginal investors in options on growth and value indices exhibit different degrees of risk aversion, growth investors being less risk averse.

\section{Conclusion}

In this paper we analyze what happens if securities are designed not by a benevolent social planner, or a derivatives exchange, or by companies issuing financial assets based on the hitherto nontraded cash-flows of closely-held real assets, but by large traders such as investment banks and hedge funds. We believe this corresponds closely to what happens in actual markets, with asset innovations completing markets for certain groups of investors ("exchanges") rather than for the economy as a whole. For instance, capital-protected investment vehicles have recently stood in the spotlight again, despite the fact that such assets are largely redundant. Price-fixing retail banks sell them at a markup to their clients, and investment banks sell them at a markup to the retail banks. Investment banks in turn have the ability to hedge them in the underlying markets.

We answer the question as to which assets we should expect to see in an economy with a variety of exchanges. Interestingly, we are able to provide an explicit and minimal answer: an exchange is offered to trade the difference between its own state-price deflator and the depth-weighted economy-wide state-price deflator. Only one asset is introduced per exchange.

Depth plays a major role in this paper. If introducing a new security was costly in our model, we would see that everything else equal, the only exchanges on which innovation occurs are the deep exchanges. Shallow exchanges would be innovated upon if the gains from trade are large enough to compensate for their shallowness. One consequence is the adage, well-known to practitioners, that derivative securities can only be successful if there is sufficient demand for them from some clientele, i.e. from the end-users. This is evident in our model: no matter how many intermediaries trade on an exchange, if the depth of the end-users tends to zero (for instance if the number of investors tends to zero), trading on the exchange vanishes as well.

We are not interested in just the equilibrium asset structure. The general equilibrium nature of our setup also allows us to study welfare properties. It is far from obvious if the securities introduced by arbitrageurs in order to extract the largest profits from wedges in investors' marginal willingness to pay lead to a socially optimal outcome. Arbitrageurs are driven by mispricings and depth considerations, not 
by socially beneficial gains from trade. Still, we can show that if investors within an exchange have identical valuations, so they form a homogeneous clientele, then an equilibrium structure is socially optimal and independent of the degree of competition between arbitrageurs. However, equilibrium allocations are not socially optimal and do depend on the degree of competition. We also provide a necessary and sufficient criterion that characterizes those investors who gain and those who lose from said innovations. If investors within an exchange are heterogeneous, the equilibrium security design is no longer socially optimal. The reason is that arbitrageurs ignore the gains from trade within exchanges since they only profit from inter-exchange reallocations of resources. The equilibrium asset structure is therefore geared toward extracting the maximum inter-exchange gains from trade, at the expense of intra-exchange gains from trade.

Our paper provides a rich framework for studying a number of issues, some of which we have only barely touched on here. One is a more general concept of liquidity. Arbitrageurs provide liquidity by mediating trades, much in the same way as marketmakers do. This suggests a measure of liquidity that ties together the seemingly disparate notions of depth, bid-ask spreads, trading volume, and gains from trade. We pursue this idea in Rahi and Zigrand (2007c). Second, the arbitraging scenario we have studied in this paper, wherein all arbitrageurs are simultaneously active on all exchanges, is but one possible description of intermediation in a segmented economy. In Rahi and Zigrand (2007a) we look at the case where arbitrageurs choose a subset of exchanges on which to trade, and analyze the resulting distribution of arbitrageur activity. We are able to derive simple rules as to the optimal exchanges on which to innovate. Quite intuitively, arbitrageurs gravitate to those exchanges which, other things being equal, are deeper and stand to gain most from trading with other exchanges. We also show, for a class of economies, that a hub-spoke network, in which all arbitrageur activity is channeled through a central exchange (the "hub"), leads to higher arbitrageur profits than any other network structure. 


\section{A Appendix: Proofs}

In the Appendix we adopt matrix notation that simplifies the proofs considerably. Rather than viewing asset payoffs on exchange $k$ as random variables $d^{k}$, we stack them into an $S \times J^{k}$ matrix $R^{k}$. The $j$ 'th column of $R^{k}$ corresponds to the $j$ 'th asset, listing its payoffs in each state $s \in S$. In this notation the set of marketable payoffs $M^{k}$ is the column space of $R^{k}$, denoted by $\left\langle R^{k}\right\rangle$.

Let $\pi_{s}$ be the probability of state $s$, and denote by $\Pi$ the $S \times S$ diagonal matrix with $\pi_{s}$ at position $(s, s)$. A state-price deflator for $\left(q^{k}, R^{k}\right)$ is a vector $p \in \mathbb{R}^{S}$ such that $q^{k}=R^{k^{\top}} p .^{15}$ In other words, it is convenient to think of state-price deflators as vectors instead of random variables. Similarly, the expression $E[x y]$ can be written as $x^{\top} \Pi y$, where the random variables $x$ and $y$ are viewed as vectors in $\mathbb{R}^{S}$. In our finite-dimensional setting, the inner product space $L^{2}$ is the space $\mathbb{R}^{S}$ endowed with the inner product $(x \mid y)=x^{\top} \Pi y$. Then $x_{M^{k}}=P^{k} x$, where $P^{k}$ is the orthogonal projection operator in $L^{2}$ onto $\left\langle R^{k}\right\rangle$, given by the idempotent matrix

$$
P^{k}:=R^{k}\left(R^{k^{\top}} \Pi R^{k}\right)^{-1} R^{k^{\top}} \Pi .
$$

An explicit derivation of $P^{k}$ can be found in the proof of Lemma 3.2 below. The notation $\|\cdot\|_{2}$ stands for the $L^{2}$-norm defined by $\|x\|_{2}:=\left(x^{\top} \Pi x\right)^{\frac{1}{2}}$, for $x \in \mathbb{R}^{S}$.

Proof of Lemma 3.1 Investor $(k, i)$ 's utility can be written as

$$
U^{k, i}=\omega_{0}^{k, i}-q^{k} \cdot \theta^{k, i}+\mathbf{1}^{\top} \Pi\left(\omega^{k, i}+R^{k} \theta^{k, i}\right)-\frac{\beta^{k, i}}{2}\left(\omega^{k, i}+R^{k} \theta^{k, i}\right)^{\top} \Pi\left(\omega^{k, i}+R^{k} \theta^{k, i}\right),
$$

where 1 is the $S \times 1$ vector of ones. The first order condition for the investor's optimization problem is

$$
-q^{k}+R^{k^{\top}} \Pi \mathbf{1}-\beta^{k, i} R^{k^{\top}} \Pi\left(\omega^{k, i}+R^{k} \theta^{k, i}\right)=0,
$$

which gives us his asset demand function (recall that $\left.p^{k, i}:=\mathbf{1}-\beta^{k, i} \omega^{k, i}\right)$ :

$$
\theta^{k, i}\left(q^{k}\right)=\frac{1}{\beta^{k, i}}\left(R^{k^{\top}} \Pi R^{k}\right)^{-1}\left[R^{k^{\top}} \Pi p^{k, i}-q^{k}\right]
$$

We can now use the market-clearing condition $\sum_{i \in I^{k}} \theta^{k, i}\left(q^{k}\right)=y^{k}$ to deduce:

$$
q^{k}\left(y^{k}\right)=R^{k^{\top}} \Pi\left[p^{k}-\beta^{k} R^{k} y^{k}\right]
$$

Thus $q^{k}\left(y^{k}\right)=R^{k^{\top}} \Pi \hat{p}^{k}$, where $\hat{p}^{k}=p^{k}-\beta^{k} R^{k} y^{k}$.

\footnotetext{
${ }^{15}$ The symbol $T$ denotes "transpose." We adopt the convention of taking all vectors to be column vectors by default, unless transposed.
} 
Proof of Lemma 3.2 Using (13), we can write the Lagrangian for arbitrageur $n$ as follows:

$$
\mathcal{L}=\sum_{k}\left[p^{k}-\beta^{k} R^{k} y^{k, n}-\beta^{k} R^{k} y^{k, \backslash n}\right]^{\top} \Pi R^{k} y^{k, n}-p^{A, n} \Pi \sum_{k} R^{k} y^{k, n},
$$

where $y^{k, \backslash n}$ is the aggregate supply of assets on exchange $k$ of all arbitrageurs but $n . p^{A, n}$ is the Lagrange multiplier vector attached to the no-default constraints, and can be interpreted as a (shadow) state-price deflator of the arbitrageur. The first order conditions are:

$$
R^{k^{\top}} \Pi\left[p^{k}-\beta^{k} R^{k} y^{k, \backslash n}-2 \beta^{k} R^{k} y^{k, n}-p^{A, n}\right]=0, \quad k \in K
$$

together with complementary slackness:

$$
p^{A, n} \geq 0, \quad \sum_{k} R^{k} y^{k, n} \leq 0, \quad \text { and } \quad p^{A, n} \cdot\left[\sum_{k} R^{k} y^{k, n}\right]=0 .
$$

The existence of the multipliers follows as usual from the linearity of the inequalities, as shown in Arrow et al. (1961).

We first demonstrate that a CWE is symmetric, i.e. $y^{k, n}$ does not depend on $n$, and we can choose $p^{A, n}=p^{A}$ for all $n$. The reaction correspondence of arbitrageur $n$, for given supply of the remaining arbitrageurs $\left\{y^{k, \backslash n}\right\}$, is single-valued due to the strict concavity of the program. From the first order conditions (14) and (15),

$$
y^{k, n}=\frac{1}{\beta^{k}}\left(R^{k^{\top}} \Pi R^{k}\right)^{-1} R^{k^{\top}} \Pi\left[p^{k}-p^{A, n}\right]-y^{k}, \quad k \in K
$$

and

$$
p^{A, n} \geq 0, \quad \sum_{k} \frac{1}{\beta^{k}} P^{k}\left(p^{k}-p^{A, n}\right)-\sum_{k} R^{k} y^{k} \leq 0
$$

with complementary slackness state-by-state. In other words, there is some $p^{A, n} \geq 0$ satisfying the no-default and complementary slackness conditions so that the unique $y^{k, n}$ chosen if all others choose $y^{k, \backslash n}$ is given by (16). Many feasible $p^{A, n}$ may exist, but any $p^{A, n}$ and $\tilde{p}^{A, n}$ that represent the reaction function must satisfy $R^{k^{\top}} \Pi p^{A, n}=$ $R^{k^{\top}} \Pi \tilde{p}^{A, n}$, otherwise single-valuedness is violated.

It follows that $y^{k, n}$ cannot depend on $n$ at an equilibrium. Indeed, assume to the contrary that an equilibrium $\left\{y^{k, n}\right\}$ is such that $y^{k, n} \neq y^{k, n^{\prime}}$ for some $k$ and some pair $\left(n, n^{\prime}\right)$. Then (16) implies that $p^{A, n} \neq p^{A, n^{\prime}}$. The inequalities (17) for arbitrageurs $n$ and $n^{\prime}$ depend only on the aggregate quantities $y^{k}$, for all $k$. So given $\left\{y^{k, n}\right\}, p^{A, n^{\prime}}$ is also a valid shadow price for arbitrageur $n$. But then $R^{k^{\top}} \Pi p^{A, n}=R^{k^{\top}} \Pi p^{A, n^{\prime}}$, implying that $y^{k, n}=y^{k, n^{\prime}}$.

Having established symmetry, we can easily solve (16) for $y^{k, n}$ and verify that

$$
R^{k} y^{k, n}=\frac{1}{(1+N) \beta^{k}} \cdot P^{k}\left(p^{k}-p^{A}\right), \quad k \in K
$$


where $P^{k}$ is given by (9). This is in fact the unique solution. From (15) and (18), the complementary slackness conditions can be written as $p^{A} \geq 0$ and

$$
\begin{aligned}
\sum_{k} \frac{1}{\beta^{k}} P^{k}\left(p^{k}-p^{A}\right) & \leq 0, \\
p^{A} \cdot\left[\sum_{k} \frac{1}{\beta^{k}} P^{k}\left(p^{k}-p^{A}\right)\right] & =0 .
\end{aligned}
$$

Note that $p^{A}$ can be chosen not to depend on $N$. We will need these conditions later.

Proof of Lemma 3.3 Using (13) and (18),

$$
\begin{aligned}
& q^{k}=R^{k^{\top}} \Pi\left[p^{k}-\frac{N}{1+N} P^{k}\left(p^{k}-p^{A}\right)\right] \\
& =R^{k^{\top}} \Pi\left[p^{k}-\frac{N}{1+N}\left(p^{k}-p^{A}\right)\right] \\
& =R^{k^{\top}} \Pi\left[\frac{1}{1+N} p^{k}+\frac{N}{1+N} p^{A}\right] .
\end{aligned}
$$

Proof of Lemma 3.4 Using (18), (21) and (20), in that order, some straightforward algebra gives us the equilibrium profits of arbitrageur $n$, for asset structure $\left\{R^{k}\right\}$ :

$$
\begin{aligned}
\Phi\left(\left\{R^{k}\right\}\right) & =\sum_{k} q^{k} \cdot y^{k, n} \\
& =\frac{1}{(1+N)^{2}} \cdot \sum_{k} \frac{1}{\beta^{k}} p^{k^{\top}} \Pi P^{k}\left(p^{k}-p^{A}\right) \\
& =\frac{1}{(1+N)^{2}} \cdot \sum_{k} \frac{1}{\beta^{k}}\left(p^{k}-p^{A}\right)^{\top} \Pi P^{k}\left(p^{k}-p^{A}\right) \\
& =\frac{1}{(1+N)^{2}} \cdot \sum_{k} \frac{1}{\beta^{k}}\left\|P^{k}\left(p^{k}-p^{A}\right)\right\|_{2}^{2} .
\end{aligned}
$$

Proof of Lemma 4.1 From (12), setting $R^{k}=I$, the portfolio of agent $(k, i)$ at $p^{*}$ is $\theta^{k, i}=\frac{1}{\beta^{k, i}}\left(p^{k, i}-p^{*}\right)$. Therefore the aggregate portfolio on exchange $k$ is $\theta^{k}:=$ $\sum_{i \in I^{k}} \theta^{k, i}=\frac{1}{\beta^{k}}\left(p^{k}-p^{*}\right)$. Now the Walrasian market-clearing condition, $\sum_{k \in K} \theta^{k}=0$, gives us $p^{*}=\sum_{k \in K} \lambda^{k} p^{k}$. Moreover, $\sum_{k \in K} \lambda^{k} p^{k}=\mathbf{1}-\beta \omega$, which is nonnegative by assumption.

Proof of Lemma 4.2 Recall that $p^{*}=\sum_{k} \lambda^{k} p^{k}$ by Lemma 4.1. Under $\mathbf{S}(\mathrm{a})$, $\sum_{k} \lambda^{k} P^{k}\left(p^{k}-p^{*}\right)=P^{1} \sum_{k} \lambda^{k}\left(p^{k}-p^{*}\right)=0$. Under $\mathbf{S}(\mathrm{b}), \sum_{k} \lambda^{k} P^{k}\left(p^{k}-p^{*}\right)=$ 
$\sum_{k} \lambda^{k}\left(p^{k}-p^{*}\right)=0$. Thus $\sum_{k} \lambda^{k} P^{k}\left(p^{k}-p^{*}\right)=0$ under $\mathbf{S}$. It follows that $p^{A}=p^{*}$ satisfies the complementary slackness conditions (19) and (20). Furthermore, $p^{*} \geq 0$ by Lemma 4.1. Therefore, $p^{*}$ is a valid Lagrange multiplier for the arbitrageur's optimization problem.

In order to prove Proposition 5.1, we need to establish the following result.

Fact A.1 $\left\|P^{k} v\right\|_{2} \leq\|v\|_{2}$, for all $v \in \mathbb{R}^{S}$. Moreover, $\left\|P^{k} v\right\|_{2}=\|v\|_{2}$ if and only if $P^{k} v=v$.

Proof :

$$
\begin{aligned}
\left\|P^{k} v\right\|_{2}^{2} & =v^{\top} \Pi R^{k}\left(R^{k^{\top}} \Pi R^{k}\right)^{-1} R^{k^{\top}} \Pi v \\
& =\left(\Pi^{1 / 2} v\right)^{\top} \Pi^{1 / 2} R^{k}\left(R^{k^{\top}} \Pi R^{k}\right)^{-1} R^{k^{\top}} \Pi^{1 / 2}\left(\Pi^{1 / 2} v\right)
\end{aligned}
$$

Defining $x:=\Pi^{1 / 2} v$ and $y:=\Pi^{1 / 2} P^{k} v=\Pi^{1 / 2} R^{k}\left(R^{k^{\top}} \Pi R^{k}\right)^{-1} R^{k^{\top}} \Pi^{1 / 2} x$, we see that $\left\|P^{k} v\right\|_{2}^{2}=x \cdot y=\|x\|\|y\| \cos (\theta)$, where $\theta$ is the angle between $x$ and $y$, and where $\|x\|:=\sqrt{x \cdot x}$. Now $y \cdot y=x \cdot y \geq 0$. If $x \cdot y=0$, the result follows. Otherwise we get $\left\|P^{k} v\right\|_{2}^{2}=x \cdot y=\|x\| \sqrt{x \cdot y} \cos (\theta)$ which we can solve for $x \cdot y=\|x\|^{2} \cos ^{2}(\theta)$. We therefore find that $\left\|P^{k} v\right\|_{2}^{2}=\|x\|^{2} \cos ^{2}(\theta) \leq\|x\|^{2}=v^{\top} \Pi v=\|v\|_{2}^{2}$.

Now suppose that $\left\|P^{k} v\right\|_{2}=\|v\|_{2}$. We want to show that $P^{k} v=v$. If $x \cdot y=0$, then $x \cdot y=\left\|P^{k} v\right\|_{2}^{2}=\|v\|_{2}^{2}=0$, so that $P^{k} v=v=0$. If, on the other hand $x \cdot y>0$, then $\left\|P^{k} v\right\|_{2}=\|v\|_{2}$ implies that $\cos ^{2}(\theta)=1$, i.e. $x$ and $y$ are collinear. But $x \cdot y=y \cdot y \neq 0$. Hence $x=y$, or $P^{k} v=v$.

Proof of Proposition 5.1 Proof of $1 \Rightarrow 2$ : Suppose $p^{k}-p^{*} \in\left\langle R^{k}\right\rangle, k \in K$. Then condition $\mathbf{S}$ holds so that, from Lemma 4.2, we can choose $p^{A}=p^{*}$. From (22), noting that $P^{k}\left(p^{k}-p^{*}\right)=p^{k}-p^{*}$, equilibrium arbitrageur profits are given by

$$
\Phi=\frac{1}{(1+N)^{2}} \cdot \sum_{k} \frac{1}{\beta^{k}}\left\|p^{k}-p^{*}\right\|_{2}^{2} .
$$

In order to establish that the proposed asset structure is optimal for every arbitrageur, we need to show that

$$
\sum_{k} \lambda^{k}\left\|p^{k}-p^{*}\right\|_{2}^{2} \geq \sum_{k} \lambda^{k}\left\|P^{k}\left(p^{k}-p^{A}\right)\right\|_{2}^{2}
$$

Fact A.1 implies that

$$
\sum_{k} \lambda^{k}\left\|p^{k}-p^{*}\right\|_{2}^{2} \geq \sum_{k} \lambda^{k}\left\|P^{k}\left(p^{k}-p^{*}\right)\right\|_{2}^{2} .
$$


Furthermore, noting that $x^{\top} A x-y^{\top} A y=(x-y)^{\top} A(x+y)$, for any vectors $x, y$, and any square matrix $A$, we have

$$
\begin{aligned}
& \sum_{k} \lambda^{k}\left\|P^{k}\left(p^{k}-p^{*}\right)\right\|_{2}^{2}-\sum_{k} \lambda^{k}\left\|P^{k}\left(p^{k}-p^{A}\right)\right\|_{2}^{2} \\
& =\sum_{k} \lambda^{k}\left[\left(p^{k}-p^{*}\right)^{\top} \Pi P^{k}\left(p^{k}-p^{*}\right)-\left(p^{k}-p^{A}\right)^{\top} \Pi P^{k}\left(p^{k}-p^{A}\right)\right] \\
& =\sum_{k} \lambda^{k}\left(p^{A}-p^{*}\right)^{\top} \Pi P^{k}\left(2 p^{k}-p^{*}-p^{A}\right) \\
& =\sum_{k} \lambda^{k}\left(p^{A}-p^{*}\right)^{\top} \Pi P^{k}\left(p^{A}-p^{*}\right)+2\left(p^{A}-p^{*}\right)^{\top} \Pi \sum_{k} \lambda^{k} P^{k}\left(p^{k}-p^{A}\right) \\
& =\sum_{k} \lambda^{k}\left\|P^{k}\left(p^{A}-p^{*}\right)\right\|_{2}^{2}-2 p^{* \top} \Pi \sum_{k} \lambda^{k} P^{k}\left(p^{k}-p^{A}\right) \quad(\operatorname{using}(20)) \\
& \geq 0
\end{aligned}
$$

where the last inequality follows from (19) and the fact that $p^{*} \geq 0$. In conjunction with (25), this implies (24).

Proof of $2 \Rightarrow 3$ : Suppose an optimal asset structure $\left\{R^{k}\right\}$ is not a Nash equilibrium asset structure, i.e. an arbitrageur can deviate such that the resulting asset structure increases his payoff. Then the payoff of all arbitrageurs is higher, contradicting the optimality of the initial asset structure $\left\{R^{k}\right\}$.

Proof of $3 \Rightarrow 1$ : Suppose a Nash equilibrium asset structure $\left\{R^{k}\right\}$ does not satisfy the condition $p^{k}-p^{*} \in\left\langle R^{k}\right\rangle, k \in K$. Then (25) holds with strict inequality due to Fact A.1, implying that profits are strictly lower than (23). Thus an arbitrageur can strictly increase his payoff by introducing the asset $p^{k}-p^{*}$ on each exchange $k$ where it is not already available. This contradicts the supposition that $\left\{R^{k}\right\}$ is a Nash equilibrium asset structure.

Proof of Lemma 6.1 Using investor $(k, i)$ 's first order condition (11), we can write his utility (10) as:

$$
U^{k, i}=\omega_{0}^{k, i}+\mathbf{1}^{\top} \Pi \omega^{k, i}-\frac{\beta^{k, i}}{2} \omega^{k, i^{\top}} \Pi \omega^{k, i}+\frac{\beta^{k, i}}{2}\left\|R^{k} \theta^{k, i}\right\|_{2}^{2} .
$$

Note that $U^{k, i}$ depends on the asset structure only through the term $\left\|R^{k} \theta^{k, i}\right\|_{2}^{2}$. From (12) and (3), we see that

$$
\begin{aligned}
R^{k} \theta^{k, i} & =\frac{1}{\beta^{k, i}} P^{k}\left(p^{k, i}-\hat{p}^{k}\right) \\
& =\frac{1}{\beta^{k, i}} P^{k}\left[\left(p^{k, i}-p^{k}\right)+\frac{N}{1+N}\left(p^{k}-p^{A}\right)\right],
\end{aligned}
$$

so that

$$
W^{k, i}:=\beta^{k, i}\left\|R^{k} \theta^{k, i}\right\|_{2}^{2}=\frac{1}{\beta^{k, i}}\left\|P^{k}\left[\left(p^{k, i}-p^{k}\right)+\frac{N}{1+N}\left(p^{k}-p^{A}\right)\right]\right\|_{2}^{2} .
$$


Proof of Proposition 6.3 Suppose the initial asset structure $\left\{R^{k}\right\}$ satisfies $\mathbf{S}$. Then, from Lemma 4.2 , we can choose $p^{A}=p^{*}$. Therefore,

$$
\left\|P^{k}\left(p^{k}-p^{A}\right)\right\|_{2}=\left\|P^{k}\left(p^{k}-p^{*}\right)\right\|_{2} \leq\left\|p^{k}-p^{*}\right\|_{2},
$$

using Fact A.1. The result now follows from Proposition 6.2.

Proof of Proposition 6.4 Let the pre- and post-innovation asset structures be, respectively, $\left\{R^{k}\right\}$ and $\left\{\bar{R}^{k}\right\}$, with projection matrices $\left\{P^{k}\right\}$ and $\left\{\bar{P}^{k}\right\}$. Since $\left\langle R^{k}\right\rangle \subset$ $\left\langle\bar{R}^{k}\right\rangle$, we have $P^{k} \bar{P}^{k}=P^{k}$. Moreover, both asset structures satisfy $\mathbf{S}$, so that we can choose $p^{A}=p^{*}$ in both cases, from Lemma 4.2. Let

$$
\zeta^{k, i}:=\left(p^{k, i}-p^{k}\right)+\frac{N}{1+N}\left(p^{k}-p^{A}\right)
$$

We have $\left\|P^{k} \zeta^{k, i}\right\|_{2}=\left\|P^{k} \bar{P}^{k} \zeta^{k, i}\right\|_{2} \leq\left\|\bar{P}^{k} \zeta^{k, i}\right\|_{2}$, using Fact A.1. The result now follows from Lemma 6.1 . 


\section{References}

Acharya, V. and Bisin, A. (2006). Optimal financial-market integration and security design. Journal of Business, 78(6):2397-2433.

Allen, F. and Gale, D. (1988). Optimal security design. Review of Financial Studies, 1(3):229-263.

Allen, F. and Gale, D. (1994). Financial Innovation and Risk Sharing. MIT Press.

Allen, F. and Santomero, A. M. (1997). The theory of financial intermediation. Journal of Banking and Finance, 21:1461-85.

Arrow, K., Hurwicz, L., and Uzawa, H. (1961). Constraint qualifications in maximization problems. Naval Research Logistics Quarterly, 8(2):175-191.

Blackburn, D., Goetzmann, W., and Ukhov, A. (2006). Risk aversion and clientele effects. Mimeo, Department of Finance, Indiana University Bloomington.

Chen, Z. and Knez, P. J. (1995). Measurement of market integration and arbitrage. Review of Financial Studies, 8(2):287-325.

Culbertson, J. (1957). The term-structure of interest rates. Quarterly Journal of Economics, 71:485-517.

Cuny, C. J. (1993). The role of liquidity in futures market innovations. Review of Financial Studies, 6(1):57-78.

Da, Z. and Gao, P. (2006). Clientele change, liquidity shock, and the return on financially distressed stocks. Mimeo, Kellogg School of Management, Northwestern University.

Demange, G. and Laroque, G. (1995). Optimality of incomplete markets. Journal of Economic Theory, 65(1):218-232.

DeMarzo, P. (2005). The pooling and tranching of securities: A model of informed intermediation. Review of Financial Studies, 18(1):1-35.

DeMarzo, P. and Duffie, D. (1999). A liquidity-based model of security design. Econometrica, 67(1):65-99.

Dowd, K., Blake, D., Cairns, A., and Dawson, P. (2006). Survivor swaps. Journal of Risk and Insurance, 73(1):1-17.

Duffie, D. and Jackson, M. (1989). Optimal innovation of futures contracts. Review of Financial Studies, 2(3):275-296.

Duffie, D. and Rahi, R. (1995). Financial market innovation and security design: An introduction. Journal of Economic Theory, 65(1):1-42. 
Elul, R. (1999). Welfare-improving financial innovation with a single good. Economic Theory, 13(1):25-40.

Engle, R. F. and Sarkar, D. (2006). Premium-discounts and exchange traded funds. Journal of Derivatives, Summer:27-45.

Gabaix, X., Krishnamurthy, A., and Vigneron, O. (2007). Limits of arbitrage: Theory and evidence from the mortgage-backed securities market. Journal of Finance, 62(2):557-595.

Gabszewicz, J. J. and Vial, J.-P. (1972). Oligopoly 'a la Cournot' in a general equilibrium analysis. Journal of Economic Theory, 4(3):381-400.

Lewis, K. (1999). Trying to explain home bias in equities and consumption. Journal of Economic Literature, 37(2):571-608.

Magill, M. and Quinzii, M. (1996). Theory of Incomplete Markets, Volume 1. MIT Press.

Mas-Colell, A. (1982). The Cournotian foundations of Walrasian equilibrium theory: an exposition of recent theory. In Hildenbrand, W., editor, Advances in Economic Theory. Cambridge University Press.

Massa, M., Peyer, U., and Tong, Z. (2005). Limits of arbitrage and corporate financial policy. CEPR Discussion Paper, No. 4829.

Modigliani, F. and Sutch, R. (1966). Innovations in interest rate policy. American Economic Review, 56(2):178-197.

Postlethwayt, M. (1757). The Universal Dictionary of Trade and Commerce. J. Knapton, 4th edition.

Rahi, R. (1995). Optimal incomplete markets with asymmetric information. Journal of Economic Theory, 65(1):171-197.

Rahi, R. and Zigrand, J.-P. (2007a). Arbitrage networks. Mimeo, London School of Economics.

Rahi, R. and Zigrand, J.-P. (2007b). Cournotian foundations for competitive equilibria with restricted consumption or restricted participation. Mimeo, London School of Economics.

Rahi, R. and Zigrand, J.-P. (2007c). A theory of strategic intermediation and endogenous liquidity. Mimeo, London School of Economics.

Shiller, R. (1993). Macro Markets: Creating Institutions for Managing Society's Largest Economic Risks. Clarendon Series, Oxford University Press. 
Tufano, P. (1989). Financial innovation and first-mover advantages. Journal of Financial Economics, 25(2):213-240.

Willen, P. (2005). New financial markets: Who gains and who loses. Economic Theory, 26(1):141-166.

Zigrand, J.-P. (2004). A general equilibrium analysis of strategic arbitrage. Journal of Mathematical Economics, 40(8):923-952.

Zigrand, J.-P. (2006). Endogenous market integration, manipulation and limits to arbitrage. Journal of Mathematical Economics, 42(3):301-314. 